\section{Zika virus-related hypertensive iridocyclitis}

\section{Iridociclite hipertensiva associada à infecção por Zika vírus}

Dear Editor:

The epidemic of Zika virus infection in Brazil has lead to the description of new complications and manifestations such as Guillain-Barré syndrome in adults and microcephaly in newborns ${ }^{(1,2)}$. Zika virus is a flavivirus transmitted to humans primarily through the bite of an infected Aedes species mosquito(3). It was first isolated and described in Africa, later spreading to Asia, Micronesia, Oceania, and to the Americas ${ }^{(2)}$.

It is thought that only 1 in 5 people infected with the Zika virus will become symptomatic ${ }^{(3)}$. The most common systemic manifestations include: fever, arthralgia, malaise, and skin rash ${ }^{(4,5)}$. More recently, retinal abnormalities were described in children with microcephaly attributed to Zika virus infection during pregnancy ${ }^{(6)}$.

The purpose of this letter is to describe a case of bilateral hypertensive iridocyclitis attributed to Zika virus in an otherwise healthy young male.

A 39-year-old male physician was clinically diagnosed with Zika virus infection. This occurred in a neighborhood with an outbreak of this disease. He presented with classic signs of fever, diffuse maculopapular rash, and severe arthralgia. Systemic work-up ruled out other possible infectious such as Dengue, CMV, Herpes Simplex, Toxoplasmosis, Syphilis, Rubella, spondyloarthropathies, rheumatic diseases, and systemic vasculitis.

One week after the systemic manifestations the patient complained of bilateral ocular discomfort for near tasks, blurry vision, and mild redness. Best-corrected visual acuity was 20/40 in each eye. Slit-lamp examination revealed moderate ciliary injection, mild anterior chamber reaction $(1+$ cells), and miosis in both eyes. Intraocular pressure (Goldmann applanation tonometry) was 40 and $28 \mathrm{mmHg}$ in right and left eyes, respectively.

He was treated with topical medications (steroids, cycloplegic and hypotensive agents) for several weeks. This achieved improvement of visual acuity, lowering of intraocular pressure, and complete resolution of symptoms.

Although no specific protein-chain reaction (PCR) for Zika virus has been performed, it is very likely that this bilateral hypertensive iridocyclitis occurred secondary to Zika virus. Since it has been shown that the virus penetrates the blood-brain and ocular barriers, many other ocular findings (in addition to conjunctivitis and retinal abnormalities) might be observed in the future. Physicians should be attentive to ocular complaints when treating patients with Zika virus infection and refer patients to a specialist for complete ocular examination.

Bruno M. Fontes ${ }^{1}$

Submitted for publication: January 15, 2016

Accepted for publication: January 18, 2016

Centro de Microcirurgia \& Diagnóstico, Rio de Janeiro, RJ, Brazil.

Funding: No specific financial support was available for this study.

Disclosure of potential conflicts of interest: None of the authors have any potential conflicts of interest to disclose.

Corresponding author: Bruno Machado Fontes. Av. Ataulfo de Paiva 135/1418 - Rio de Janeiro, RJ - 22440-032 - Brazil - E-mail: fontesbrunom@gmail.com

\section{REFERENCES}

1. Fauci AS, Morens DM. Zika Virus in the Americas - Yet Another Arbovirus Threat. N Engl J Med. 2016 Jan 13. (Epub ahead of print).

2. Zika virus outbreaks in the Americas. Wkly Epidemiol Rec. 2015 Nov 6;90(45):609-10

3. Marcondes CB, Ximenes MF. Zika virus in Brazil and the danger of infestation by Aedes (Stegomyia) mosquitoes. Rev Soc Bras Med Trop. 2015 Dec 22 (Epub ahead of print).

4. Dyer O. Zika virus spreads across Americas as concerns mount over birth defects. BMJ. Dec 23;351:h6983.

5. Triunfol M. A new mosquito-borne threat to pregnant women in Brazil. Lancet Infect Dis. Published online: December 23, 2015.

6. Ventura CV, Maia M, Bravo-Filho V, Góis AL, Belfort Jr R. Zika virus in Brazil and macular atrophy in a child with microcephaly. The Lancet, Vol. 387, No. 10015, p228. Published online: January 7, 2016.

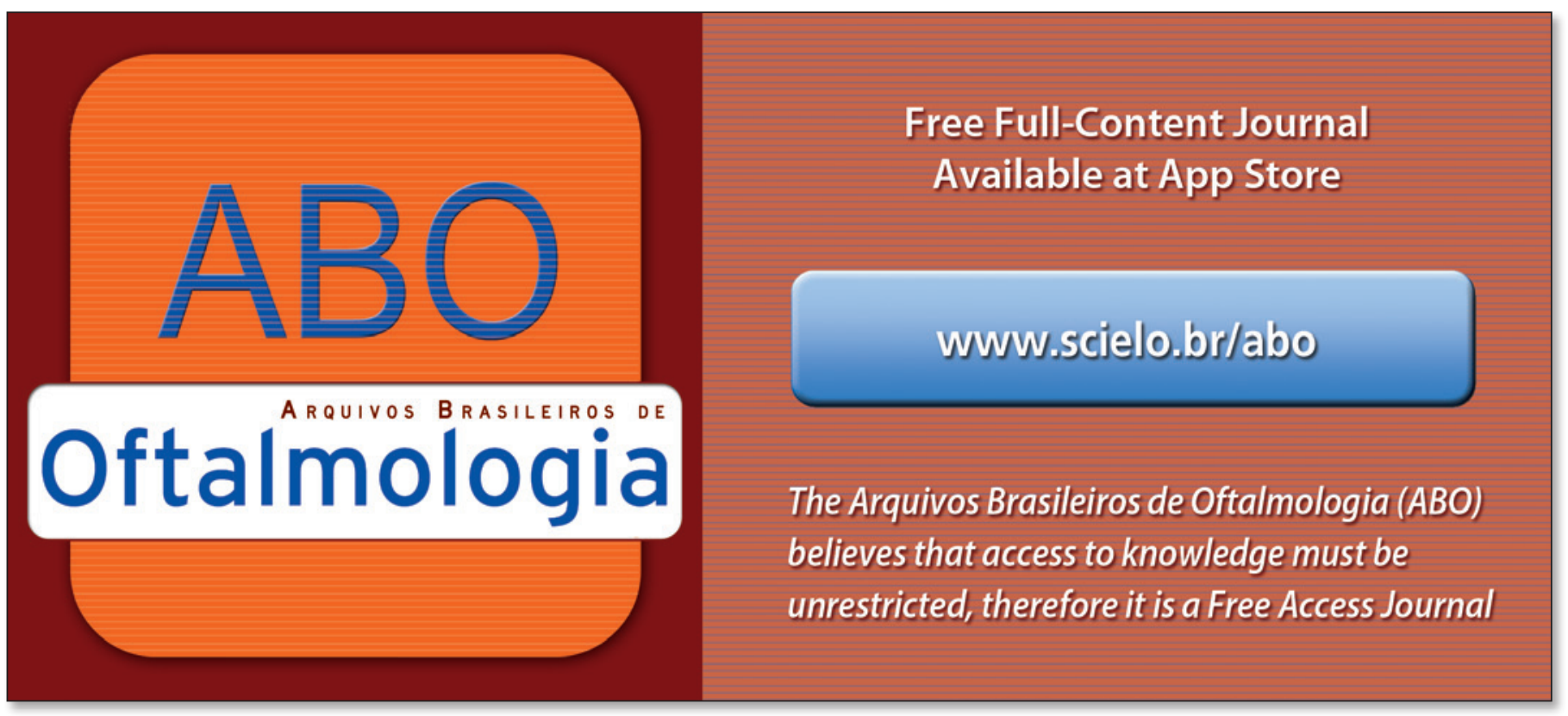

